\title{
Lean Umbilical Cord - a Case Report
}

\author{
Thin-Cord-Komplex - ein Fallbericht
}

Authors

Affiliations
N. Rippinger ${ }^{1}$, M. Elsässer ${ }^{1}$, P. Sinn ${ }^{2}$, C. Sohn ${ }^{1}$, H. Fluhr ${ }^{1}$

${ }^{1}$ Universitäts-Frauenklinik, Frauenheilkunde und Geburtshilfe, Universitätsklinikum Heidelberg, Heidelberg, Germany

${ }^{2}$ Department of Pathology, University of Heidelberg, Heidelberg, Germany

\begin{abstract}
Key words
- umbilical cord anomaly

- thin-cord syndrome

- placental insufficiency

- Wharton's jelly

Schlüsselwörter

- Nabelschnuranomalie

- Thin-Cord-Komplex

- Plazentainsuffizienz

- Wharton-Sulze
\end{abstract}

Deutsche Version unter: http://dx.doi.org/ $10.1055 / \mathrm{s}-0042-112812$

\section{Abstract \\ $\nabla$}

The "lean" umbilical cord (also known as thincord syndrome) is a comparatively rare anomaly of the umbilical cord, which has seldom been described in the medical literature. We report on a 35 -year-old women who presented to us at $29+4$ weeks gestation with vaginal bleeding and cervical incompetence subsequently complicated not only by premature rupture of membranes but also acute placental insufficiency requiring emergency caesarean section under general anaesthesia at $31+2$ weeks gestation. At surgery no obvious cause for the acute placental insufficiency - such as placental abruption, cord prolapse or true knot of the umbilical cord - was found. Other possible causes such as vasa praevia or placenta praevia had previously been excluded sonographically on admission for vaginal bleeding. The only notable intraoperative finding was a macroscopically extremely thin umbilical cord.

\section{Case History}

received 18.4.2016 revised 19.6.2016 accepted 19.7.2016

\section{Bibliography}

DOI http://dx.doi.org/

10.1055/s-0042-112812

Geburtsh Frauenheilk 2016; 76:

1186-1188 @ Georg Thieme

Verlag KG Stuttgart · New York . ISSN 0016-5751

\section{Correspondence}

Nathalie Rippinger,

Assistenzärztin

UniversitätsKlinikum Heidelberg

Frauenklinik

Im Neuenheimer Feld 660

69120 Heidelberg

Germany

Nathalie.Rippinger@

med.uni-heidelberg.de
A 35-year-old gravida 2 para 1 presented to our antenatal clinic at $29+4$ weeks gestation with mild vaginal bleeding. Speculum examination revealed under period strength, bright red haemorrhage from the cervical canal. On ultrasound examination there was no evidence of retroplacental haematoma, placenta praevia or vasa praevia. A slender fetus was noted with growth parameters on the 5th percentile, normal amniotic fluid and normal umbilical cord (UC) doppler parameters. The cervix was shortened - length $28 \mathrm{~mm}$ without funneling. The patient had previously been admitted to our department at $23+0$ weeks gestation with brownish coloured spotting and had received steroids for fetal lung maturation

\section{Zusammenfassung}

Der sogenannte Thin-Cord-Komplex ist eine relativ seltene Nabelschnurpathologie, die bisher in der Literatur nur wenig beschrieben wurde. Wir berichten über eine 35-jährige Patientin, die sich seit der $29+4$ Schwangerschaftswoche in unserer stationären Behandlung bei vaginaler Blutung sowie Zervixinsuffizienz befand und bei der es im klinischen Verlauf nicht nur zu einem vorzeitigen Blasensprung, sondern auch zu einer akuten Plazentainsuffizienz mit Entbindung per Notsectio in Intubationsnarkose in der $31+2$ Schwangerschaftswoche kam. Intraoperativ zeigte sich kein Anhaltspunkt für Ursachen einer akuten Plazentainsuffizienz wie vorzeitige Plazentalösung, Nabelschnurvorfall bei vorzeitigem Blasensprung oder Nabelschnurknoten. Andere Ursachen wie Vasa praevia oder Placenta praevia bei vaginaler Blutung als Aufnahmegrund wurden bereits im Vorfeld sonografisch ausgeschlossen. Lediglich fiel intraoperativ eine makroskopisch äußerst dünne Nabelschnur auf.

because of a retroplacental haematoma. At this stage a large placental lacuna was considered in the differential diagnosis. Subsequent regular outpatient follow-up at our antenatal clinic showed no further evidence of retroamnial or retrochorionic haematoma.

At $29+4$ weeks gestation steroids were repeated ( 2 doses of $12 \mathrm{mg}$ betamethasone 24 hours apart). A vaginal swab was positive for anaerobe bacteria and GBS (no gardnerella) which was treated with local fluomizin. On re-evaluation at $30+0$ weeks, after 48 hours without further vaginal bleeding, the cervix was unchanged at $28 \mathrm{~mm}$ and no funneling. However, the fibronectin test was positive (60 $\mathrm{ng} / \mathrm{ml}$ ) and the patient agreed to a further period of in-patient observation. Subsequently, at $30+4$ weeks gestation, preterm rupture of mem- 


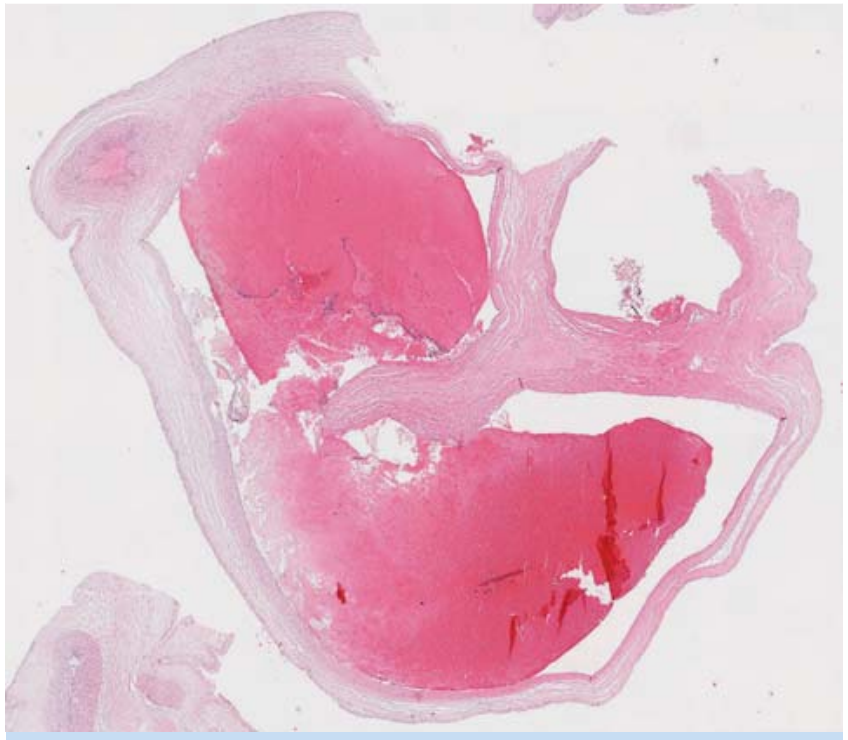

Fig. 1 Histological cross section of umbilical cord showing essential absence of Wharton's jelly; cord otherwise normal with three blood vessels.

branes (PROM) occurred. In view of positive group B streptococcus status intravenous antibiotics (infectocillin) and daily monitoring of infection markers were commenced. Laboratory parameters including CRP levels remained normal and repeat doppler ultrasound at $30+5$ weeks was unremarkable. Following the positive PROM test, PROM ultrasound did show oligohydramnios. At $31+2$ weeks gestation a routine CTG revealed multiple, recurrent decelerations with fetal heart rate (FHR) down to $80 \mathrm{bpm}$ (beats per minute) in the absence of uterine contractions. The situation did not improve on changing the patient's position but FHR recovered following a partusisten (fenoterol hydrobromide) bolus. The patient was immediately transferred to our delivery room where tocolysis was continued with a partusisten infusion. In addition to CTG monitoring the fetal heart rate was verified repeatedly by ultrasound; umbilical artery doppler examination was performed repeatedly (resistance index [RI] 0.51, positive end diastolic flow [EDF]). The placenta was sonographically unremarkable and there was no vaginal bleeding. In our delivery room fetal bradycardia recurred (FHR $60 \mathrm{bpm}$ ) and fetal heart rate recovered again after a new partusisten bolus. Due to this repetitive situation of fetal bradycardia and decelerations it was decided to perform urgent caesarean section in spinal anaesthesia. On arrival in the operating theatre, however, fetal bradycardia was noted once again and emergency caesarean was then performed under general anaesthesia. A male infant with mild respiratory depression was delivered from a normal cephalic presentation (Apgar at 1/5/10 minutes: $7 / 8 / 8$; arterial $\mathrm{pH}$ : 7.26 ; venous pH: 7.43; BE: -5.2). Intraoperatively there were no signs of placental abruption. The only notable finding was that the umbilical cord appeared, macroscopically, unusually thin.

There were no postoperative complications. On consultation with the patient, and on her request, the placenta and umbilical cord were sent for histological examination.

The anatomical pathology findings (macroscopic) were as follows: Placenta disc-shaped, weight $315 \mathrm{~g}$, size $13 \times 11 \times 2,8 \mathrm{~cm}$ with centrally inserting, $18 \mathrm{~cm}$ long section of three-vessel, macroscopically lean (diameter: $0.4 \mathrm{~cm}$ ) umbilical cord. No umbilical cord knots. Placental surface on incision unremarkable.
Umbilical cord histology: Wharton's jelly essentially absent. UC otherwise normal with three blood vessels ( $\bullet$ Fig. $\mathbf{1}$ ).

In summary: the placenta was assessed as eutrophic for the gestational age (32nd week of pregnancy) but with premature placental aging consistent with the clinical suspicion of placental insufficiency; the thin UC, with a maximum diameter of $4 \mathrm{~mm}$, was consistent with a diagnosis of lean umbilical cord (or socalled thin-cord syndrome).

\section{Discussion}

Lean umbilical cord is an UC anomaly characterised by reduced or completely absent Wharton's jelly. The fetal umbilical cord consists of one vein, transporting oxygen-rich blood from the placenta to the fetus, and two arteries, returning nutrient-poor, carbon dioxide-rich blood back to the mother. Wharton's jelly surrounds the three UC vessels providing a flexible protective layer against vessel compression, kinking and other mechanical forces, thus assuring the fetal blood supply and removal of metabolic waste products.

In a case report published in 1961 Samuel Pike Hall states his conviction that the absence or reduction of Wharton's jelly could be responsible for many unexplained intrauterine deaths, and that too little significance was attributed to this pathology in routine clinical practice [4]. Raio et al. provide a detailed description of UC diameter as it develops through the course of a pregnancy [8]. Our patient delivered in the 32nd week of pregnancy. According to their data normal average cord diameter at this gestation is $16.59 \mathrm{~mm}$, and the histopathologically determined cord diameter of $4 \mathrm{~mm}$ in our case would correlate with the normal average cord thickness in the 13th or 14th week of pregnancy. Raio and colleagues further describe an increase in UC thickness up until the 33rd and 34th weeks of gestation to a maximum diameter of $16.72 \mathrm{~mm}$, and a subsequent decrease in thickness to an average of $15.59 \mathrm{~mm}$ at term [8]. Weissman et al. also describe the changes the umbilical cord undergoes during pregnancy using nomograms, observing a maximum UC diameter of up to $18 \mathrm{~mm}$ between the 38th and 39th weeks of pregnancy [10]. Both publications (Raio et al. and Weissman et al.) provide detailed tables of UC diameter for the respective gestational ages $[8,10]$. Weissman et al. use measures of cord diameter taken in the longitudinal plane, whereas Raio et al. measure the cord in cross section (transverse plane). Both publications recommend taking measurements as close to the fetal abdominal UC insertion as possible.

Another feature of our case that was typical of a lean umbilical cord was the ultrasound finding of a slender fetus with growth along the 5th percentile in the presence of normal UC doppler parameters (small for gestational age, SGA). Bruch et al. describe an association between reduced Wharton's jelly, hypoplastic UC blood vessels and fetal intrauterine growth retardation due to resulting placental insufficiency without pathological doppler parameters [1]. Raio et al. also conclude that fetuses with thin umbilical cords are at increased risk of growth below the 10th percentile (SGA or IUGR) compared to those with normal UC diameters and more often show signs of stress at birth $[6,7]$. They state that fetuses shown to have thin umbilical cords on ultrasound from 20 weeks gestation onwards have a 4.4 times increased risk of being SGA at birth [7]. When ultrasound was conducted after 25 weeks gestation the risk was increased to 12.5 times [7]. In addition, they report that babies with thin UCs were significantly 
more likely than those with normal thickness cords to have a 5minute Apgar score < 7, and oligohydramnios was more common [7].

It should however be noted that a lean umbilical cord does not necessarily always result in complications. Raio and Ghezzi et al. highlight that many pregnancies remain uncomplicated despite a lean UC on ultrasound examination, and that additional criteria should be sought in order to identify higher risk situations. For example, according to Ghezzi et al., the strongest predictor of poor outcome is the umbilical vein cross-sectional area, i.e. the diameter of the vein with respect to UC cross-sectional diameter [3], and report significantly increased numbers of perinatal fetal death and increased neonatal intensive care admission rates when the umbilical vein area is below the 10th percentile [3]. There is also a significant association between increased IUGR rate and lean umbilical cord where the UC area is below the 2.5 percentile. Other studies agree with these results and recommend the measurement of UC area as a screening parameter to detect patients with values below the 10th percentile, allowing monitoring to be intensified as appropriate $[1,7,9]$.

\section{Conclusion}

Today it is known that a lean umbilical cord due to reduced or completely absent Wharton's jelly is associated with a worse neonatal outcome in affected children $[2,3,5,7,9]$. In the case presented here the combination of a lean UC and reduced amniotic fluid secondary to PROM was most likely responsible for reduced fetal perfusion, which in turn produced recurrent decelerations on CTG prompting urgent delivery. Of note, the CTG only became pathological relatively late, which could be explained by the combination of PROM, lean UC and the fetal position, resulting in mechanical UC compression. This case illustrates that in the presence of oligohydramnios, SGA or IUGR it is not only important to assess fetal doppler parameters and the number of UC vessels, but also cord morphology, since in rare cases this can play an important role. It would seem sensible to assess UC morphology sonographically on a routine basis, or at least in the presence of SGA or IUGR of uncertain cause, thus enabling detection of women who might benefit from more intensive antenatal monitoring. In our case prior knowledge of the presence of a lean UC would not have altered obstetric management since close observation and monitoring were already indicated due to SGA and PROM. Notably, however, postpartum knowledge of this diagnosis was important for the patient involved as it provided an explanation for her preterm delivery, and the low recurrence risk was significant from a psychological point of view with respect to the planning of possible future pregnancies.

\section{Conflict of Interest}

$\nabla$

None.

\section{References}

1 Bruch JF, Sibony O, Benali K et al. Computerized microscope morphometry of umbilical vessels from pregnancies with intrauterine growth retardation and abnormal umbilical artery Doppler. Hum Pathol 1997; 28: 1139-1145

2 Di Naro E, Ghezzi F, Raio L et al. Umbilical cord morphology and pregnancy outcome. Eur J Obstet Gynecol Reprod Biol 2001; 96: 150-157

3 Ghezzi F, Raio L, Gunter Duwe D et al. Sonographic umbilical vessel morphometry and perinatal outcome of fetuses with a lean umbilical cord. J Clin Ultrasound 2005; 33: 18-23

4 Hall SP. The thin-cord syndrome. A review with a report of two cases. Obstet Gynecol 1961; 18: 507-509

5 Labarrere C, Sebastiani M, Siminovich M et al. Absence of Wharton's jelly around the umbilical arteries: an unusual cause of perinatal mortality. Placenta 1985; 6: 555-559

6 Raio L, Ghezzi F, Di Naro E et al. Umbilical cord morphologic characteristics and umbilical artery Doppler parameters in intrauterine growthrestricted fetuses. J Ultrasound Med 2003; 22: 1341-1347

7 Raio L, Ghezzi F, Di Naro E et al. Prenatal diagnosis of a lean umbilical cord: a simple marker for the fetus at risk of being small for gestational age at birth. Ultrasound Obstet Gynecol 1999; 13: 176-180

8 Raio L, Ghezzi F, Di Naro E et al. Sonographic measurement of the umbilical cord and fetal anthropometric parameters. Eur J Obstet Gynecol Reprod Biol 1999; 83: 131-135

9 Silver RK, Dooley SL, Tamura RK et al. Umbilical cord size and amniotic fluid volume in prolonged pregnancy. Am J Obstet Gynecol 1987; 157: 716-720

10 Weissman A, Jakobi P, Bronshtein M et al. Sonographic measurements of the umbilical cord and vessels during normal pregnancies. J Ultrasound Med 1994; 13: 11-14 